\title{
Analisa Risiko Keselamatan dan Kesehatan Kerja (K3) Terhadap Kecelakaan Kerja Serta Lingkungan dengan Menggunakan Metode Hazard and Operability Study (HAZOP) pada Proses Scrapping Kapal di Bangkalan Madura
}

\author{
Abdul Khamid, Yeyes Mulyadi, dan Mukhtasor \\ Departemen Teknik Kelautan, Fakultas Teknologi Kelautan, \\ Institut Teknologi Sepuluh Nopember (ITS) \\ e-mail: yeyes@oe.its.ac.id
}

\begin{abstract}
Abstrak-Kapal merupakan moda transpotasi untuk memindahkan penumpang atau barang dari satu tempat ke tempat lain melalui laut. Kapal dengan umur lebih dari 25 tahun secara umum tidak dapat dioperasikan lagi karena adanya Peraturan Menteri Perhubungan pada tahun 2005. Ketika umur kapal bertambah, maka kapal tersebut menjadi tidak efisien untuk dioperasikan. Scrapping kapal pada saat ini dianggap sebagai solusi terbaik kapal yang tidak beroperasi. Kegiatan Scrapping kapal meliputi persiapan peralatan dan pekerja, bersandarnya kapal, pemotongan dan pengiriman material hasil scrapping. Tujuan utama dari penelitian ini adalah menyusun skenario risiko dan menilai risiko yang ada pada industri scrapping kapal di Bangkalan Madura dengan metode Hazard and Operability Study (HAZOP). Metode HAZOP merupakan suatu cara identifikasi suatu risiko yang terjadi pada setiap pekerjaan dengan menggabungkan 2 kata penting yaitu parameter dan guideword menghasilkan penyimpangan (deviasi) hingga memberikan usulan tindakan pencegahan pada risiko kecelakaan. Analisis data dilakukan mulai mempersiapkan perlengkapan dan kondisi pekerja hingga pengiriman hasil scrapping. Metode berfungsi untuk mengetahui tingkat/level kecelakan pekerja dan dampak terhadap lingkungan di usaha scrapping kapal. Risiko terekstrim diperoleh oleh pembersihan sisa bahan bakar/oli dengan menggunakan sabun dengan nilai 19,32. Tindakan pencegahan meliputi Memperhatikan faktor-faktor keselamatan pada waktu perencanaan, pembangunan sistem keamanan, sistem keselamatan bagi pekerja ataupun lingkungan, hingga pengawasan atau pengecekan setiap pekerjaan, menyelidiki kerusakan yang terjadi pada kecelakaan dan memelihara kalender kejadian.
\end{abstract}

Kata Kunci-Kapal, Scrapping, HAZOP.

\section{PENDAHULUAN}

Kabupaten Bangkalan merupakan salah satu tempat galangan scrapping kapal yang dikelola secara tradisional di daerah Tanjung Jati Madura [1] seperti pada Gambar 1 Scrapping kapal menggunakan metode (beaching) dan sebatas usaha pemotongan kapal menjadi lembaran lembaran plat besi [2]. Metode Beaching memiliki kelemahan yaitu pada saat pasang surut dan gelombang laut (Suastiks K dan Akriananta W, 2017) [1]. Docking kapal dilakukan karena adanya proses perawatan (maintenace) dan pembongkaran kapal. Perawatan kapal meliputi pengecatan ulang, pengecekan kebocoran kapal dll. Kapal yang telah melampaui 25 tahun dari awal produksi akan mengalami penurunan performa pada waktu operasional kapal. Sehingga solusi yang paling tepat adalah daur ulang kapal. Proses daur ulang kapal meliputi bersandarnya kapal, pengupasan, pemotongan dan penanganan material secara tepat. Proses ini membutuhkan perlengkapan yang mempuni, sistem kerja yang sesuai dengan $\mathrm{K} 3$, serta memerlukan kopetensi bagi karyawannya.

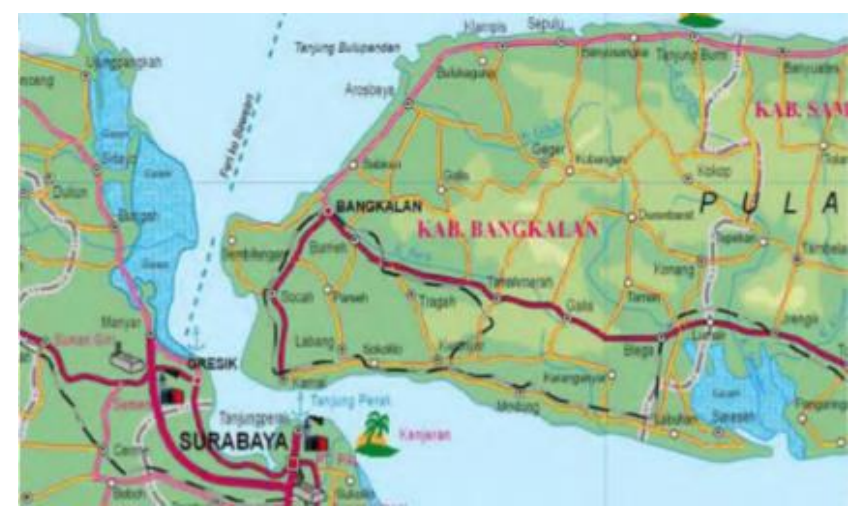

Gambar 1 Peta Kabupaten Bangkalan [3].

Hazard atau bahaya merupakan sumber potensi kerusakan atau keadaanyang memiliki potensi merugikan manusia karena mengandung bahaya yang dapat menimbulkan kecelakaan ataupun mengganggu keselamatan dan kesehatan seseorang. Urutan terjadinya kecelakaan kerja menurut teori yaitu kurangnya kontrol atau sistem manajemen menimbulkan adanya penyebab tidak langsung dan langsung yang menimbulkan kerugian. Hazard atau bahaya dapat diminimalisir dengan menggunakan keselamatan dan kesehatan kerja (K3). Menurut [4] K3 adalah suatu program yang dibuat pekerja maupun pengusaha sebagai upaya mencegah timbulnya kecelakan dan penyakit akibat kerja dengan cara mengenali hal - hal potensi menimbulkan kecelakaan dan penyakit akibat kerja serta tindakan antisipasif apabila terjadi kecelakaan dan penyakit akibat kerja.

HAZOP adalah studi keselamatan yang sistematis, berdasarkan pendekatan sistematik ke arah penilaian keselamatan dan proses pengoperasian peralatang yang kompleks atau produksi [5]. Tujuannya untuk mengidentifkasi kemungkinan bahaya yang muncul dalam 
proses pengelolaan di perusahaan menghilangkan sumber utama kecelakaan, seperti ledakan, beracun dan kebakaran [6].

Berdadarkan latar belakang yang telah diuraikan diatas, maka penulis tertarik untuk melakukan tugas akhir dengan judul "Analisa Risiko Keselamatan dan Kesehatan Kerja (K3) serta Lingkungan dengan Metode Hazard and Operability (HAZOP) pada Proses Scrapping Kapal di Bangkalan Madura".

\section{A. Pengumpulan Data}

\section{METODOLOGI PENELITIAN}

Studi ini di menggunakan CV Jaya Bersama sebagai objek studi. CV Jaya Bersama adalah salah satu perusahan yang bergerak di bidang scrapping kapal di Bangkalan. Pengambilan data berdasarkan data proyek scrapping kapal yang ada di lapangan. Adapun data yang digunakan antara lain:

1. Data kapal dan kapasitas galangan

2. Prosedur scrapping kapal, teknologi dan fasilitas yang dimiliki

3. Wawancara dan kuisioner untuk mengetahui risik risiko kecelakaan kerja dan dampak lingkungan dalam proses scrapping kapal

\section{B. Pengukuran Tingkat Kelelahan Pekerja menggunakan Kuisinonr}

Kelelahan kerja merupakan bagian dari permasalahan umum yang sering dijumpai pada tenaga kerja. Kelelahan kerja adalah gejala yang berhubungan dengan penurunan efisiensi kerja, keterampilan, kebosanan, serta peningkatan kecemasan. Metode yang digunakan kuisioner subyective feeting of fatigue (Industrial Fatigue Research Committee) [7] yaitu :

Tabel 1.

Kelelelahan Pekeja

Perasaan berat di kepala
Menjadi lelah seluruh tubuh
Kaki merasa berat
Menguap
Merasa kacau pikiran
Menjadi mengantuk
Merasakan beban pada mata
Kaku dan canggung dalam bergerak
Tidak seimbang dalam berdiri
Mau berbaring
Marasa susah berpikir
Lelah bicara
Menjadi gugup
Tidak dapat berkonsentrasi
Sulit memuatkan perhatian
Cenderung untuk lupa
Kurang kepeceryaan diri
Cemas terhadap sesuatu
Tidak dapat mengontrol sikap
Tidak tekun dalam kerja
Tidak tekun dalam pekerjaan
Sakit kepala
Kekakuan dibahu
Merasa nyeri dipunggung
Merasa pernafasan tertekan
Haus
Suara serak
Merasa pening
Tremor pada anggota badan
Merasa kurang sehat

\section{Pengukuran Tingkat Kelelahan Metode Cardiovascular}

Peningkatan denyut nadi mempunyai peran yang sangat penting dalam peningkatan cardiac output dari istirahat sampai kerja maksimum. menurut [8] menentukan klasifikasi beban kerja berdasarkan dengan peningkatan denyut nadi kerja dibandingkan dengan denyut nadi maksimum karena beban kardiovaskular (cardiovascular load $=\%$ load) [9]. yang dihitung dengan rumus sebagai berikut :

$\% \mathrm{CVL}=100 \mathrm{X}$ (denyut nadi kerja-denyut nadi istirahat) / denyut nadi maksimum-denyut nadi istirahat (1)

*denyut nadi maksimum $=220$ - umur (Asrand and Rodahl, 1997)

Dari hasil perhitungan \% CVL tersebut kemudian dibandingkan dengan klasifikasi sebagai berikut :

- $\mathrm{X} \leq 30 \% \quad=$ Tidak terjadi kelelahan

$-30 \% \leq \mathrm{X} \leq 60 \%=$ Diperlukan perbaikan

$-60 \% \leq \mathrm{X} \leq 80 \%=$ Kerja dalam waktu singkat

- $80 \% \leq \mathrm{X} \leq 100 \%=$ Diperlukan tindakan segera

$-\mathrm{X}>100 \% \quad=$ Tidak diperbolehkan beraktifitas beraktifitas

\section{D.Analisa Risiko Hazard and Operability (HAZOP)}

Analisa risiko ini menggunakan metode Hazard and Operability Studi (HAZOP) suatu metode identifikasi risiko dengan cara yang terstruktur dan rapi. dengan menggunakan aturan DNV dan buku (Hazard Analysis Techniques for System Safety by Clifton A. Ericson, I) [6]. (Langkah langkah penyusunan HAZOP, antara lain :

1. Identifikasi masalah tentang proses scrapping kapal

2. Penentuan Parameter dan Guideword. Ketentuan berdasarkan DNV dan buku Hazard Analysis Techniques for System Safety by Clifton A. Ericson, I [6]. seperti dibawah ini :

Parameter : Arus (gas, cairan, arus listrik), suhu, tekanan, pisahkan (settle, filter, centrifuge), reaksi, kurangi (menggiling, menghancurkan, dll.), corrode, memisahkan, inspeksi, pengawasan, viskositas, instrumen, korosi, getaran, aliran data perangkat lunak, tingkat, komposisi, campuran, erode, menguras, membersihkan, mempertahankan, matikan, memulai, erosi, syok, massa jenis.

Guideword : Tidak, penurunan, peningkatan, kebalikan, selain itu, lainnya, fluktuasi, awal waktu, terlambat, serta (lebih dari), bagian dari, kebalikan, dimana lagi, sebelum/sesudah, lebih lambat/lebih cepat, gagal, fungsi tidak sengaja terjadi.

\section{E. Penentuan Matriks Risiko}

Untuk merubah skala diskriptif menjadi skala kuantitatif. Ketentuan yang berdasarkan aspek pekerja dan lingkungan pada Tabel 2 likehood dan Tabel 3 konsekuensi bagi pekerja dan lingkungan. 
Tabel 2

\begin{tabular}{|c|c|c|c|}
\hline \multicolumn{2}{|c|}{ Likehood } & \multirow[b]{2}{*}{ Kualitatif } & \multirow[b]{2}{*}{ Semikualitatif } \\
\hline Level & Uraian & & \\
\hline 1 & Jarang terjadi & $\begin{array}{l}\text { Dapat dipikirkan tetapi } \\
\text { tidak hanya saat keadaan } \\
\text { ekstrim }\end{array}$ & $\begin{array}{l}\text { Kurang dari } 1 \text { kali } \\
\text { dalam } 10 \text { tahun }\end{array}$ \\
\hline 2 & $\begin{array}{l}\text { Kemungkinan } \\
\text { Kecil }\end{array}$ & $\begin{array}{l}\text { Belum terjadi tetapi bisa } \\
\text { muncul/ terjadi pada } \\
\text { suatu waktu }\end{array}$ & $\begin{array}{l}\text { Terjadi } 1 \text { kali per } \\
10 \text { tahun }\end{array}$ \\
\hline 3 & Mungkin & $\begin{array}{l}\text { Seharusnya terjadi dan } \\
\text { mungkin telah menjadi } \\
\text { muncul disini atau } \\
\text { ditempat lain }\end{array}$ & $\begin{array}{l}1 \text { kali per } 5 \text { tahun } \\
\text { sampai } 1 \text { tahun kali } \\
\text { pertahun }\end{array}$ \\
\hline 4 & $\begin{array}{l}\text { Kemungkinan } \\
\text { Besar }\end{array}$ & $\begin{array}{l}\text { Dapat terjadi dengan } \\
\text { mudah, mungkin } \\
\text { muncul dalam keadaan } \\
\text { yang paling banyak } \\
\text { terjadi }\end{array}$ & $\begin{array}{l}\text { Lebih dari } 1 \text { kali } \\
\text { per tahun hingga } 1 \\
\text { kali per bulan }\end{array}$ \\
\hline 5 & Hampir Pasti & $\begin{array}{l}\text { Sering terjadi, } \\
\text { diharapkan muncul } \\
\text { dalam keadaan yang } \\
\text { paling banyak terjadi }\end{array}$ & $\begin{array}{l}\text { Lebih dari } 1 \text { kali } \\
\text { per bulan }\end{array}$ \\
\hline
\end{tabular}

Tabel 3.

ASC WHS Risk Management Procedures 2015 Executive [11] dan Environmental Risk Assessment - Proposed Sandy Rigde Facility [12].

\begin{tabular}{|c|c|c|c|}
\hline \multicolumn{4}{|c|}{ Consequences/Severity } \\
\hline Level & Uraian & Keparahan Cidera & $\begin{array}{l}\text { Keparahan } \\
\text { Lingkungan }\end{array}$ \\
\hline 1 & $\begin{array}{l}\text { Tidak } \\
\text { Signifikan }\end{array}$ & $\begin{array}{l}\text { Cidera yang perawatan } \\
\text { pertolongan pertama - } \\
\text { luka ringan, memar, } \\
\text { benjolan }\end{array}$ & $\begin{array}{l}\text { Tidak ada } \\
\text { pencemaran }\end{array}$ \\
\hline 2 & Kecil & $\begin{array}{l}\text { membutuhkan } \\
\text { perawatan medis dan } \\
\text { atau waktu yang hilang } \\
\text { dari tempat kerja. }\end{array}$ & $\begin{array}{l}\text { Pelepasan limbah } \\
\text { didalam tanpa } \\
\text { keluar }\end{array}$ \\
\hline 3 & Sedang & $\begin{array}{l}\text { Cedera serius } \\
\text { menyebabkan rawat } \\
\text { inap. }\end{array}$ & $\begin{array}{l}\text { Pelepasan limbah } \\
\text { di dalam bantuan } \\
\text { dari luar } \\
\text { (lingkungan) }\end{array}$ \\
\hline 4 & Berat & $\begin{array}{l}\text { Cedera yang } \\
\text { mengancam nyawa } \\
\text { atau beberapa luka } \\
\text { serius menyebabkan } \\
\text { rawat inap }\end{array}$ & $\begin{array}{l}\text { Pelepasan limbah } \\
\text { tidak ada efek } \\
\text { merugikan }\end{array}$ \\
\hline 5 & Bencana & $\begin{array}{l}\text { Mengakibatkan korban } \\
\text { meninggal }\end{array}$ & $\begin{array}{l}\text { Pelepasan racun } \\
\text { keluar dengan } \\
\text { efek yang } \\
\text { merugikan }\end{array}$ \\
\hline
\end{tabular}

\section{F Analisa Matriks Risiko}

Penentuan matriks tingkat risiko ini menggunakan perkalian antara probability/ kemungkinan kejadian kecelakaan terjadi dan berdampak pada lingkungan. Serta konsekuensi yang terjadi pada kejadian kecelakaan bagi pekerja dan berdampak bagi lingkungan. Seperti rumus dibawah ini :

$$
\mathrm{R}=\mathrm{P} \times \mathrm{C}
$$

Dimana : $\quad \mathrm{R}=$ Tingkat risiko (Rendah, Sedang, Tinggi,

$$
\begin{aligned}
& \text { Ekstrim) } \\
& \mathrm{P}=\text { Nilai kemungkinan (1 sampai 5) } \\
& \mathrm{C}=\text { Nilai konsekuensi (1 sampai 5) }
\end{aligned}
$$

Penentuan tingkat risiko menggunakan penentuan nilai frekuensi dan dampak risiko menggunakan perhitungan nilai rata - rata (Average Index ) yang merumuskan oleh Majid dan McCaffer (1997) sebagai berikut :
Average Index $(\mathrm{AI})=\frac{\frac{\sum_{1}^{5} \operatorname{aix} \mathrm{i}}{N}}{N}$

Dimana : ai $=$ Konstanta penilai $(1,2,3,4,5)$

$\mathrm{xi}=$ Frekuensi Responde

$\mathrm{N}=$ Frekuensi Responden

Tabel 4

Matriks Risiko

\begin{tabular}{rccccc}
\hline \hline Likelihood & \multicolumn{5}{c}{ Consequence } \\
\hline & Negligible & Minor & Moderate & Major & Severe \\
\hline $\begin{array}{r}\text { Almost } \\
\text { certain }\end{array}$ & Low & Medium & High & $\begin{array}{c}\text { Very } \\
\text { High }\end{array}$ & $\begin{array}{c}\text { Very } \\
\text { High }\end{array}$ \\
\hline Likely & Low & Medium & High & High & $\begin{array}{c}\text { Very } \\
\text { High }\end{array}$ \\
\hline Possible & Low & Medium & Medium & High & High \\
\hline Unlikely & Low & Low & Medium & Medium & High \\
\hline Rare & Low & Low & Low & Medium & Medium \\
\hline \hline
\end{tabular}

\section{G. Tindakan Guna Mengendalikan Risiko}

Tindakan berguna untuk mengendalikan risiko/ masalah yang terjadi pada saat kegiatan operasional berlangsung.

\section{HASIL DAN DISKUSI}

A.Identifikasi Bahaya Operasional bagi pekerjan dan Lingkungan

1. Bahaya Pekerjaan Persiapan Peralatan dan Pekerja

2. Bahaya Pekerjaan Penarikan kapal di Pesisir Pantai

3. Bahaya Pekerjaan Pemotongan di Kapal

4. Bahaya Pekerjaan Pengangkatan Hasil Pemotongan dari Kapal

5. Bahaya Pekerjaan Pemotongan di Darat

6. Bahaya Pekerjaan Pengangkatan menuju ke truk

7. Bahaya Pekerjaan Tangka Bahan Bakar dan Oli

8. Bahaya Pekerjaan Pembersihan Tangki Ballast

9. Pekerjaan Permbersihan Limbah Domestik

10. Bahaya Pekerjaan Penyimpanan alat

Perhitungan untuk mengukur kelelahan pekerja menggunakan kuisioner subyective feeting of fatigue (Industrial Fatigue Research Committee) dan perhitungannya denyut nadi.

1. Divisi Pemotongan Kapal

Dapat dilihat pada Gambar 2 untuk hasil tingkat

kelelahan pada pekerja divisi pemotongan kapal :

PE 1: Pengawas 1 PP 1: Pemotongan 1

PP 2 : Pemotongan 2 PP 3 : Pemotongan 3

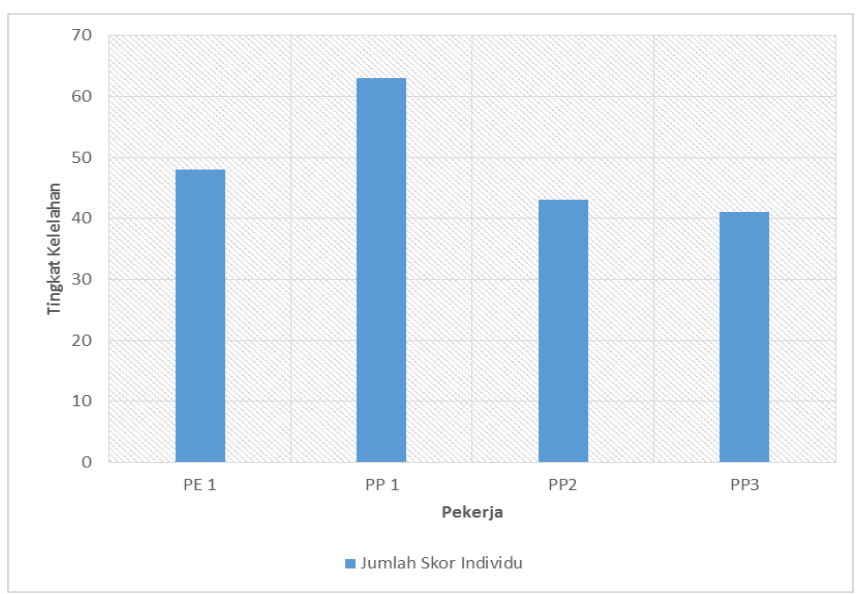

Gambar 2. Tingkat Pelemahan Kegiatan, Motivasi, dan Fisik pada Pekerjaan Divisi Pemotongan Kapal. 
Tabel 5.

Tolak Ukur Kelelahan Pekerja

\begin{tabular}{|c|c|c|c|c|}
\hline $\begin{array}{l}\text { Tingkat } \\
\text { kelelahan }\end{array}$ & & $\begin{array}{l}\text { Total skor } \\
\text { individu }\end{array}$ & $\begin{array}{l}\text { Klasifikasi } \\
\text { kelelahan }\end{array}$ & Tindakan Perbaikan \\
\hline & 1 & $30-52$ & Rendah & $\begin{array}{l}\text { Belum diperlukan } \\
\text { perbaikan }\end{array}$ \\
\hline & 2 & $53-75$ & Sedang & $\begin{array}{l}\text { Mungkin diperlukan } \\
\text { perbaikan }\end{array}$ \\
\hline & 3 & $76-98$ & Tinggi & Diperlukan tindakan \\
\hline & 4 & $99-120$ & Sangat tinggi & $\begin{array}{l}\text { Diperlukan tindakan } \\
\text { menyeluruh sesegera } \\
\text { mungkin }\end{array}$ \\
\hline
\end{tabular}

\section{Divisi Mobilitas}

Dapat dilihat pada Gambar 3 untuk hasil tingkat kelelahan pada pekerja divisi mobilitas.
HE 1 : Helper 1
SU 1 : Supir 1
OP 1 : Operator crane

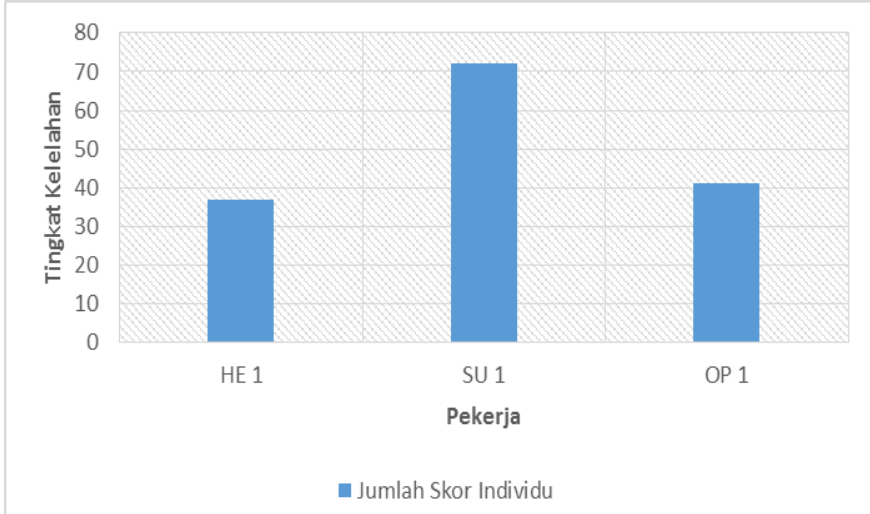

Gambar 3. Tingkat Pelemahan Kegiatan, Motivasi, dan Fisik pada Pekerjaan Divisi Mobilitas.

\section{Divisi Kuli Panggul}

Dapat dilihat pada Gambar 4 untuk hasil tingkat kelelahan pada pekerja divisi kuli panggul :

$\begin{array}{llll}\text { PS 1 } & \text { : Pengawas Seluruhnya } & \text { KK 1 } & \text { : Kepala Kuli 1 } \\ \text { KK 2 } & \text { : Kepala Kuli 2 } & \text { KP 1 } & \text { : Kuli Panggul 1 } \\ \text { KP 2 } & \text { : Kuli Panggul 2 } & \text { KP 3 } & \text { : Kuli Panggul 3 } \\ \text { KP 4 } & \text { : Kuli Panggul } & \text { KP 5 } & \text { : Kuli Panggul 5 }\end{array}$

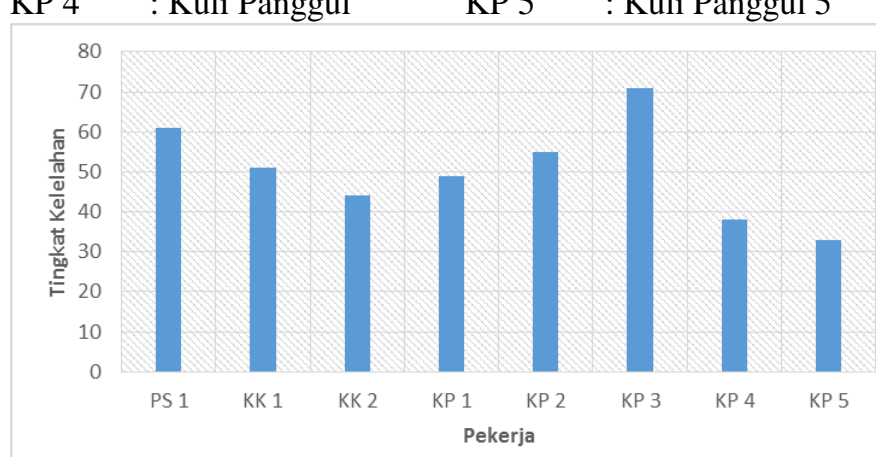

Jumlah Skor Individu

Gambar 4 Tingkat Pelemahan Kegiatan, Motivasi, dan Fisik pada Pekerjaan Divisi Kuli Panggul

Perhitungan untuk mengukur kelelahan pekerja perhitungannya denyut nadi.

1. Divisi Pemotongan

Perhitungan dilaksanakan pada sebelum bekerja dan sedang melaksanakan pekerjaan divisi pemotongan Gambar 5

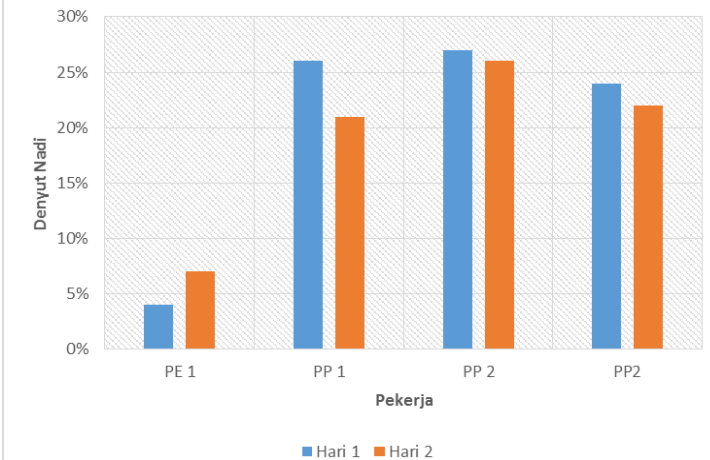

Gambar 5. Tingkat kelelahan Divisi Pemotongan.

Tabel 6.

Tolak Ukur Kelelahan Menggunakan Denyut Nadi

\begin{tabular}{ll}
\hline \hline $\mathrm{x} \leq 30 \%$ & Tidak terjadi kelelahan \\
\hline $30 \% \leq 60 \%$ & Diperlukan perbaikan \\
$60 \% \leq 80 \%$ & Kerja dalam waktu singkat \\
$80 \leq 100 \%$ & Diperlukan tindakan segera \\
$\geq 100 \%$ & Tidak boleh diperbolehkan aktifitas \\
\hline \hline
\end{tabular}

2. Divisi Mobilitas

Perhitungan dilaksanakan pada sebelum bekerja dan sedang melaksanakan pekerjaan pada divisi mobilitas Gambar 6

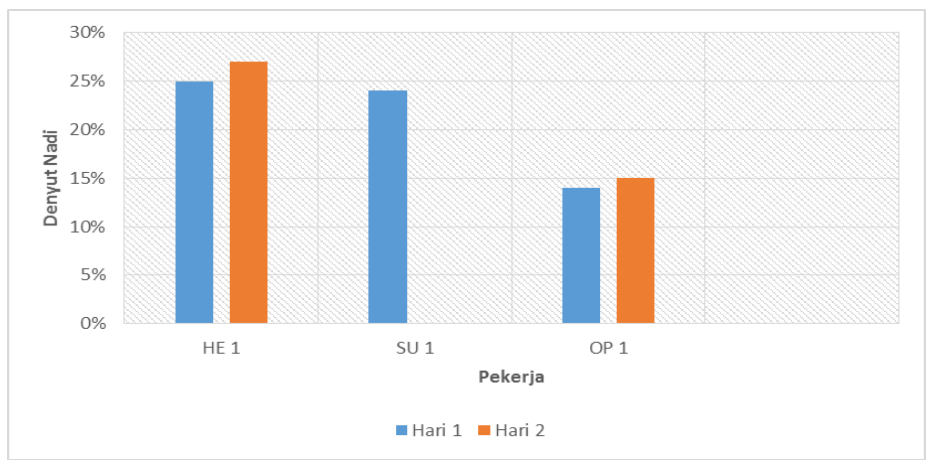

Gambar 6. Tingkat kelelahan divisi mobilitas.

\section{Divisi Kuli Panggul}

Perhitungan dilaksanakan pada sebelum bekerja dan sedang melaksanakan pekerjaan pada divisi kuli panggul Gambar 7:

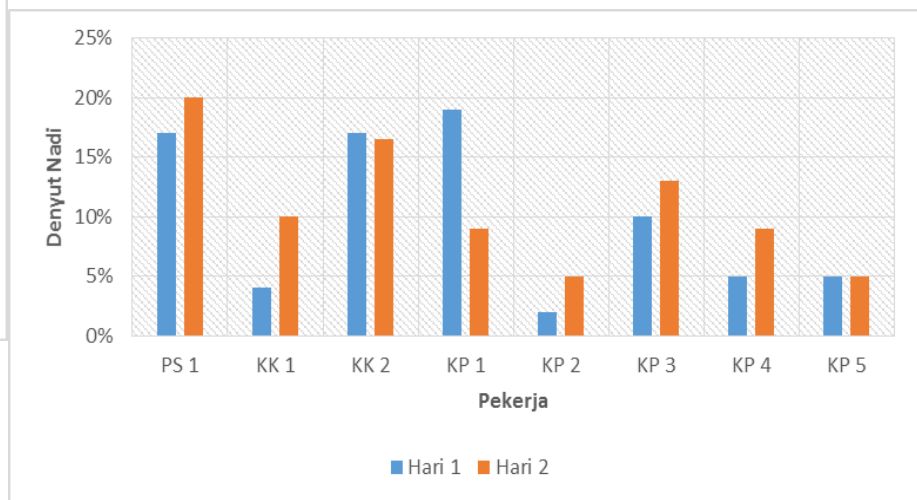

Gambar 7. Divisi kuli panggul.

Perhitungan Tingkat Kemungkinan terjadi dan Tingkat Keparahan pada Tabel 7 
Tabel 7.

Perhitungan Tingkat Keparahan dan Tingkat Konsekuensi

\begin{tabular}{|c|c|c|c|c|c|c|}
\hline No & Kejadian & $\mathrm{L}$ & $\mathrm{R}$ & $\mathrm{C}$ & $\mathrm{R}$ & $\mathrm{LXC}$ \\
\hline 1a & $\begin{array}{l}\text { Tidak adanya rencana kegiatan yang pasti dan } \\
\text { teratur }\end{array}$ & 2.8 & 3 & 1 & 1 & 2.8 \\
\hline $1 \mathrm{~b}$ & Lalai dengan kondisi peralatan dan pekerja & 3.4 & 3 & 1.4 & 1 & 4.76 \\
\hline $2 \mathrm{a}$ & Kelelahan pekerja & 2.6 & 3 & 1.6 & 2 & 4.16 \\
\hline $2 b$ & Terputusnya tali/rantai & 3.4 & 3 & 2.6 & 3 & 8.84 \\
\hline $2 \mathrm{c}$ & Crane roboh & 2.8 & 3 & 1.6 & 2 & 4.48 \\
\hline $3 a$ & $\begin{array}{l}\text { Kebocoran selang gas untuk pemotong an kapal, } \\
\text { regulator tidak dipasang an dengan baik }\end{array}$ & 3.4 & 3 & 1.8 & 2 & 6.12 \\
\hline $3 \mathrm{~b}$ & $\begin{array}{l}\text { Tidak memisahkan peralatan yang mudah } \\
\text { terbakar }\end{array}$ & 2 & 2 & 2 & 2 & 4 \\
\hline $3 c$ & Tumpuhan kaki kurang nyaman & 3.2 & 3 & 1.8 & 2 & 5.76 \\
\hline $3 \mathrm{~d}$ & Asap & 3.4 & 3 & 1.6 & 2 & 5.44 \\
\hline $3 e$ & Cahaya pemotongan yang menyala & 5 & 5 & 1 & 1 & 5 \\
\hline $3 \mathrm{f}$ & Percikan api masuk ke mata atau badan & 5 & 5 & 1 & 1 & 5 \\
\hline $4 a$ & $\begin{array}{l}\text { Karena beban y ang dipindah tidak sesuai } \\
\text { kapasitas crane }\end{array}$ & 1.6 & 2 & 3 & 3 & 4.8 \\
\hline $4 \mathrm{~b}$ & Kapasitas tali kurang memadahi & 1.4 & 1 & 2.4 & 2 & 3.36 \\
\hline $4 \mathrm{c}$ & Operator terpeleset saat menaiki crane & 2 & 2 & 1.8 & 2 & 3.6 \\
\hline $4 \mathrm{f}$ & Mata iritasi & 5 & 5 & 1.4 & 1 & 7 \\
\hline $4 \mathrm{~g}$ & Pekerja kurang focus & 4.2 & 5 & 1.2 & 1 & 5.04 \\
\hline $5 \mathrm{a}$ & $\begin{array}{l}\text { Kebocoran selang gas untuk pemotongan kapal, } \\
\text { regulator tidak dipasangan dengan baik }\end{array}$ & 3.4 & 4 & 1.6 & 2 & 5.44 \\
\hline No & Kejadian & $\mathrm{L}$ & $\mathrm{R}$ & $\mathrm{C}$ & $\mathrm{R}$ & $\mathrm{LXC}$ \\
\hline $5 b$ & $\begin{array}{l}\text { Tidak memisahkan peralatan yang mudah } \\
\text { terbakar }\end{array}$ & 1.8 & 2 & 1.8 & 2 & 3.24 \\
\hline $5 \mathrm{c}$ & Memisahkan peralatan yang tidak digunakan & 4.4 & 5 & 1.6 & 2 & 7.04 \\
\hline $5 \mathrm{~d}$ & Tumpuhan kaki kurang nyaman & 5 & 5 & 1.4 & 1 & 7 \\
\hline $5 \mathrm{e}$ & Beban kerja berlebihan dan asap & 4.4 & 4 & 1.2 & 1 & 5.28 \\
\hline $5 \mathrm{f}$ & Cahaya pemotongan yang menyala & 5 & 5 & 1 & 1 & 5 \\
\hline $5 \mathrm{~g}$ & Percikan api masuk ke mata atau badan & 5 & 5 & 1 & 1 & 5 \\
\hline $6 \mathrm{a}$ & Kapasitas tali kurang memadahi & 4.4 & 4 & 2 & 2 & 8.8 \\
\hline $6 \mathrm{~b}$ & Operator terpeleset saat menaikicrane & 5 & 5 & 1.8 & 2 & 9 \\
\hline $6 \mathrm{c}$ & $\begin{array}{l}\text { Pada saat pemindahkan material, pekerjean tidak } \\
\text { menghentikan pekerjaan }\end{array}$ & 2.6 & 3 & 1.6 & 2 & 4.16 \\
\hline $6 \mathrm{~d}$ & $\begin{array}{l}\text { Wadah untuk hasil pemotongan yang kecil } \\
\text { berkarat }\end{array}$ & 3.8 & 4 & 1.6 & 2 & 6.08 \\
\hline $6 \mathrm{e}$ & $\begin{array}{l}\text { Adanya beban yang jatuh mengakibatkan } \\
\text { getaran dan suara yang besar }\end{array}$ & 5 & 5 & 1 & 1 & 5 \\
\hline $6 \mathrm{f}$ & Mata iritasi & 5 & 5 & 1.2 & 1 & 6 \\
\hline $6 \mathrm{~g}$ & Memilih jahur yang kurang tepat & 4.8 & 5 & 1 & 1 & 4.8 \\
\hline $7 \mathrm{a}$ & Ada benda yang menyumbat aliran selang & 4 & 4 & 1 & 1 & 4 \\
\hline $7 \mathrm{~b}$ & Selang bocor & 3.6 & 4 & 1 & 1 & 3.6 \\
\hline $7 \mathrm{c}$ & $\begin{array}{l}\text { Sisa bahan bakar/oli yang dibersihkan } \\
\text { menggunakan air sabun }\end{array}$ & 4.2 & 4 & 4.6 & 5 & 19.32 \\
\hline $7 \mathrm{~d}$ & Pompa mati & 1 & 1 & 3.8 & 4 & 3.8 \\
\hline $7 \mathrm{e}$ & Karena pembersihan belum selesai & 1 & 1 & 2.4 & 2 & 2.4 \\
\hline $8 \mathrm{a}$ & Ada benda yang menyumbat aliran selang & 4.2 & 4 & 1 & 1 & 4.2 \\
\hline $8 b$ & Pembuangan langsung air ballast di laut & 4 & 4 & 4.4 & 4 & 17.6 \\
\hline $8 \mathrm{c}$ & Pompa mati & 3.8 & 4 & 1 & 1 & 3.8 \\
\hline 9 & Pembersihan limbah domestik & 4 & 4 & 1 & 1 & 4 \\
\hline 10a & Tidak adana tempat penyimpanan peralatan & 2.6 & 3 & 1.2 & 1 & 3.12 \\
\hline $10 \mathrm{~b}$ & Menaruh barang dengan semabarangan & 2.4 & 2 & 1 & 1 & 2.4 \\
\hline
\end{tabular}

\section{B. Pentuaan Matriks Risiko}

Pentuan matriks risiko hasil dari perkalian rata - rata probability dan rata - rata konsekuensi setiap pekerjaan dan dampak terhadap lingkungan. Hasil dapat dilihat pada Tabel 8 .
Tabel 8.

Hasil Matrik Risiko semua Pekerjaan

\begin{tabular}{|c|c|c|c|c|c|}
\hline \multirow{2}{*}{ Likelihood } & \multicolumn{5}{|c|}{ Consequence } \\
\cline { 2 - 6 } & Negligible & Minor & Moderate & Major & Severe \\
\hline $\begin{array}{c}\text { Almost } \\
\text { certain }\end{array}$ & $\begin{array}{l}(3 \mathrm{E})(3 \mathrm{~F})(4 \mathrm{~F}) \\
(4 \mathrm{G})(5 \mathrm{D})(5 \mathrm{~F}) \\
(5 \mathrm{G})(6 \mathrm{E})(6 \mathrm{~F}) \\
(6 \mathrm{G})\end{array}$ & $(5 \mathrm{C})(6 \mathrm{~B})$ & & & \\
\hline Likely & $\begin{array}{l}(4 \mathrm{E})(5 \mathrm{E})(7 \mathrm{~A}) \\
(7 \mathrm{~B})(8 \mathrm{~A})(8 \mathrm{C}) \\
(9)\end{array}$ & $(6 \mathrm{~A})(6 \mathrm{D})(5 \mathrm{~A})$ & & $(8 \mathrm{~B})$ & $(7 \mathrm{C})$ \\
\hline Possible & $(1 \mathrm{~A})(1 \mathrm{~B})(10 \mathrm{~A})$ & $\begin{array}{l}(2 \mathrm{~A})(2 \mathrm{C})(3 \mathrm{~A}) \\
(3 \mathrm{C})(3 \mathrm{D})(6 \mathrm{C})\end{array}$ & (2B) & & \\
\hline Unlikely & $(10 \mathrm{~B})$ & $(3 \mathrm{~B})(4 \mathrm{C})(5 \mathrm{~B})$ & (4A)(4D) & & \\
\hline Rare & & $(7 \mathrm{~B})(7 \mathrm{E})$ & & (7D) & \\
\hline
\end{tabular}

Tabel 9.

Penentuan Matriks Risiko

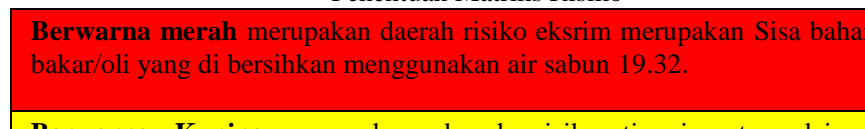

Berwarna Kuning merupakan daerah risiko tinggi antara lain Pembuangan langsung air ballast di laut 17.6

\section{Berwarnan Hijau merupakan daerah risiko sedang}

Memisahkan peralatan yang tidak digunakan 7.04, (Pemotongan didarat)

- Kebocoran selang gas untuk pemotongan kapal, (Pemotongan didarat)

- Regulator tidak dipasangan dengan baik 5.44 (Pemotongan didarat),

- Operator terpeleset saat menaiki crane 9, (Pengangkatan menuju truk)

- Kapasitas tali kurang memadahi 8.8, (Pengangkatan menuju truk)

- Wadah untuk hasil pemotongan yang kecil berkarat 6.08 (Pengangkatan menuju truk)

- Pada saat pemindahkan material pekerjean tidak menghentikan pekerjaan 4.16 (Pengangkatan menuju truk)

- Kelelahan pekerja 4.16 (Penarikan kapal)

- Crane roboh 4.48 (Penarikan kapal),

- Kebocoran selang gas untuk pemotongan kapal, regulator tidak dipasangan dengan baik 6.12, (Pemotongan dikapal)

- Tumpuhan kaki kurang nyaman 5.76, (Pemotongan dikapal)

- Asap 5.44 (Pemotongan dikapal),

- Karena beban yang dipindah tidak sesuai kapasitas crane 4.8 , (Pengangkatan dari kapal)

- Pada saat pemindahkan material, (Pengangkatan dari kapal)

- pekerjean tidak menghentikan pekerjaan 5.6 (Pengangkatan dari kapal),

- Pompa mati 3.8, (Pembersihan tangki bahan bakar/oli).

- Selang bocor 3.6 (Pembersihan tangki bahan bakar/oli).

Berwarna Biru merupakan daerah risiko rendah antara lain:

- Cahaya pemotongan yang menyala 5, (Pemotongan di kapal)

- Percikan api masuk ke mata atau badan 5 (Pemotongan di kapal)

- Tidak memisahkan peralatan yang mudah terbakar 4 (Pemotongan di kapal)

- Mata iritasi 7, (Pengangkatan dari kapal)

- Pekerja kurang fokus 5.04 (Pengangkatan dari kapal)

- Operator terpeleset saat menaiki crane 3.6 (Pengangkatan dari kapal)

- Kapasitas tali kurang memadahi 3.36 (Pengangkatan dari kapal)

- Tumpuhan kaki kurang nyaman 7 (Pemotongan di darat)

- Tidak memisahkan peralatan yang mudah terbakar 3.24(Pemotongan di darat)

- Ada benda yang menyumbat aliran selang 4 (Permbersihan tangki bahan bakar)

- Selang bocor 3.6 (Permbersihan tangki bahan bakar) 


\begin{tabular}{l}
$\begin{array}{l}\text { - Karena pembersihan belum selesai } 2.4 \text { (Permbersihan tangki bahan } \\
\text { bakar) }\end{array}$ \\
\hline $\begin{array}{l}\text { - Ada benda yang menyumbat aliran selang } 4.2 \text { (Pembersihan tangki } \\
\text { ballasting) }\end{array}$ \\
\hline - Pompa mati 3.8 (Pembersihan tangki ballasting), \\
\hline - Pembersihan limbah domestik 4 \\
- Tidak adanya rencana kegiatan yang pasti dan teratur 2.8 ( Persiapan \\
pekerja dan peralatan) \\
\hline - Lalai dengan kondisi peralatan dan pekerja 4.76 ( Persiapan pekerja dan \\
peralatan)
\end{tabular}

\section{Pengendalian Risiko}

1. Memperhatikan faktor-faktor Keselamatan pada Waktu Perencanaan dan Pembangunan Sistem Keamanan (Safety Induction)

2. Merancang Perlengkapan dan Pertimbangan Keselamatan Kerja dan Menyediakan Pakaian Pengamana (Penggunaan Alat Pelindung Diri (APD))

3. Melakukan Pengawasan yang teratur dan Mengecek serta Mengambil Tindakan untuk Menghilangkan Risiko (Toolbox Meeting)

4. Menyelidiki kejadian-kejadian yang Mengakibatkan Kerusakan dan Mengambil Inisiatif untuk melakukan Tindakan Koreksi (Safety Alert)

5. Mengembangkan Organisasi Keselamatan dan Kesehatan Kerja (K3) yang Efektif (Organisasi Panitia Pembina Keselamatan dan Kesehatan Kerja (P2K3))

6. Memelihara Catatan Safety Calender (Kalender Keamanan)

\section{KESIMPULAN}

1. Kegiatan operasional scrapping kapal di Tanjung Jati, Bangkalan Madura merupakan kegiatan yang mempunyai risiko dan bahaya yang tinggi serta dapat menimbulkan kerugian bagi pemilik usaha ataupun masyarakat yang berdekatan dengan usaha yang sedang berlangsung, baik berupa kecelakaan manusia dan dampak pencemaran lingkungan. Penilain risiko keselamatan dalam kegiatan operasional metode HAZOP Bahaya yang terjadi akibat penyimpangan pengawasan, tekanan, syok, korosi, aliran dan inspeksi

2. Analisa HAZOP yang dilakukan pada proses scrapping kapal, nilai kemungkinan terjadi dan nilai konsekuensi dilakukan berdasarkan kemungkinan dan keparahan yang terjadi 40 kejadian dari 10 node yang berpotensi terjadinya bahaya dalamn proses scrapping kapal. Tingkat konsekuensi dalam proses scrapping kapal dengan nilai 5 yang berarti risiko ekstrim adalah pembersihan sisa bahan bakar/oli dengan menggunakan sabun dan pembuangan air ballasting di laut.
3. Skala yang paling ekstrim adalah 25 Untuk kejadian yang memiliki nilai risiko ekstrim adalah pembersihan sisa bahan bakar/oli dengan menggunakan sabun 19.32

4. Pada penelitian ini, jumlah safeguard yang telah teridentifikasi pada tahap proses operasional scrappinh kapal antara lain:

a. Memperhatikan faktor-faktor Keselamatan pada Waktu Perencanaan dan Pembangunan Sistem Keamanan (Safety Induction)

b. Merancang Perlengkapan dan Pertimbangan Keselamatan Kerja dan Menyediakan Pakaian Pengamanan (Penggunaan Alat Pelindung Diri /APD)

c. Menyelidiki kejadian-kejadian yang Mengakibatkan Kerusakan dan Mengambil Inisiatif untuk melakukan Tindakan Koreksi (Toolbox Meeting)

d. Menyelidiki kejadian-kejadian yang Mengakibatkan Kerusakan dan Mengambil Inisiatif untuk melakukan Tindakan Koreksi (Safety Alarm),

e. Mengembangkan Organisasi Keselamatan dan Kesehatan Kerja (K3) yang Efektif (Organisasi Panitia Pembina Keselamatan dan Kesehatan Kerja/P2K3),

f. Memelihara Catatan (Safety Calender).

\section{DAFTAR PUSTAKA}

K. Suastiks and W. Akriananta, "Analisis pengembangang galangan daur ulang kapal ramah lingkungan di indonesia menggunakan metode ANP :Studi kasus galangan daur ulang kapal di madura, kamal," Surabaya, 2017.

[2] S. Fariya, "Analisis Teknik Ekonomis Pengembangan Ship Recycling Yard di Indonesia," Institut Teknologi Sepuluh Nopember, 2016.

[3] Aliwosin, "Analisa Potensi Sumber Daya Alam Pesisir Pantai Sembilangan Kabupaten Bangakalan sebagai Pantai Wisata," Surabaya, 2015.

[4] T. Lestari and E. Trisyulianti, "Hubungan Keselamatan dan Kesehatan Kerja (K3) dengan Produktivitas Kerja karyawan (Studi Kasus: Bagian Pengolahan PTPN VIII Gunung Mas, Bogos)," J. Manaj. IPB, vol. 1, no. 1, pp. 73-79, 2009.

[5] L. Kotek and M. Tabas, "HAZOP study with qualitative risk analysis for prioritization of corrective and preventive actions," Procedia Eng., vol. 42, no. 4, pp. 808-815, 2012.

[6] J. Dunjo, V. Fthenakis, J. Vilchez, and J. Arnaldos, "Hazard and operability (HAZOP) analysis. A literature review," Hazard Mater., vol. 173, no. 1, pp. 19-32, 2009.

[7] K. Saito, "Measurement of Fatigue in Industries," Ind. Health vol. 37, pp. 134-142, 1999.

[8] A. Manuaba and K. Vanwonterghem, "Improvement of Quality of Life. Determination of Exposure Limits for Physical Strenuous Jobs under Tropical Conditions. Final Report- CT-90019," 1996.

[9] S. Tarwaka, Bakri and L. Sudiajeng, Ergonomi untuk Keselamatan, Kesehatan Kerja dan Produktivitas. Surakarta: UNIBA Press, 2004 